\title{
Defined Daily Doses (DDD) do not accurately reflect opioid doses used in contemporary chronic pain treatment
}

Suzanne Nielsen ${ }^{1,2}$, Natasa Gisev ${ }^{1}$, Raimondo Bruno, ${ }^{1,3}$, Wayne Hall ${ }^{1,4}$, Milton Cohen ${ }^{5}$, Briony Larance $^{1}$, Gabrielle Campbell ${ }^{1}$, Marian Shanahan ${ }^{1}$, Fiona Blyth ${ }^{6}$, Nicholas Lintzeris ${ }^{2,7}$, Sallie Pearson $^{8}$, Richard Mattick ${ }^{1}$, Louisa Degenhardt ${ }^{9-11}$

1. National Drug and Alcohol Centre, University of New South Wales, Sydney 2052, Australia

2. Drug and Alcohol Services, South Eastern Sydney Local Health District, Surry Hills 2010, Australia

3. School of Medicine (Psychology), University of Tasmania, Hobart 7001, Australia

4. Centre for Youth Substance Abuse Research, University of Queensland, Royal Brisbane and Women's Hospital, Herston, Queensland 4029 Australia

5. St Vincent's Clinical School, UNSW, Darlinghurst NSW 2010, Australia

6. Concord Clinical School, University of Sydney, Sydney, 2050 Australia.

7. Discipline of Addiction Medicine, University of Sydney, NSW 2050,Australia

8. Medicines Policy Research Unit, Centre for Big Data Research in Health, University of New South Wales, 2052, Australia

9. School of Population and Global Health, The University of Melbourne, Parkville, VIC 3010 Australia

10. Murdoch Children's Research Institute, The Royal Children's Hospital, Flemington Road Parkville, VIC 3052 Australia

11. Department of Global Health, School of Public Health, University of Washington, 325 9th Avenue Seattle, WA 98104 USA

Keywords: Chronic pain, opioids, defined daily dose (DDD), oral morphine equivalent.

Running head: Defined daily doses for opioids in chronic pain

\section{Corresponding Author:}

Suzanne Nielsen

National Drug and Alcohol Research Centre, University of New South Wales

22-32 King St, Randwick, 2031, Australia

Phone + 61289361017 Fax + 61293850222

suzanne.nielsen@unsw.edu.au

This work has not been previously published or presented in any form

Funding: This study received funding from the Australian National Health and Medical Research Council (NHMRC, \#1022522). SN, NG, BL and LD are supported by NHMRC

This is the author manuscript accepted for publication and has undergone full peer review but has not been through the copyediting, typesetting, pagination and proofreading process, which may lead to differences between this version and the Version of Record. Please cite this article as doi: $10.1002 /$ pds.4168

This article is protected by copyright. All rights reserved. 
research fellowships (\#1013803, \#1091878, \#1073858 and \#1041472). The National Drug and Alcohol Research Centre at the University of NSW is supported by funding from the Australian Government under the Substance Misuse Prevention and Service Improvements Grant Fund.

Disclosures: SN, NL, RB, BL, GC and LD have all been investigators on untied investigatordriven educational grants from Reckitt Benckiser. NL, RB, BL and LD have received an untied educational grant from Mundipharma for post-marketing surveillance studies of Reformulated OxyContin®. SN and LD are investigators on untied investigator-driven educational grant funded by Indivior. These untied grants are all unrelated to the current study. MC has received payment for preparation and presentation of educational material from Mundipharma Limited. NL has received honoraria for providing professional education regarding opioid analgesic dependence and in the treatment of opioid dependence from PharmacomMedia.

This article is protected by copyright. All rights reserved. 


\begin{abstract}
Objective: To assess how well the Defined Daily Dose (DDD) metric reflects opioid utilisation among chronic non-cancer pain (CNCP) patients.

Design: Descriptive, cross-sectional study, utilising a 7-day medication diary.

Setting: Community-based treatment settings, Australia.

Subjects: A sample of 1101 people prescribed opioids for CNCP.

Methods: Opioid dose data was collected via a self-completed 7-day medication diary capturing names, strengths and doses of each medication taken in the past week. Median daily dose was calculated for each opioid. Comparisons were made to the World Health Organization's (WHO) DDD metric.
\end{abstract}

Results: WHO DDDs ranged from 0.6 to 7.1 times the median opioid doses used by the sample. For transdermal fentanyl and oral hydromorphone, the median dose was comparable with the DDD. The DDD for methadone was 0.6 times lower than the median doses used by this sample of chronic pain patients. In contrast, the DDD for oxycodone and transdermal buprenorphine, the most commonly used strong opioids for chronic pain in Australia, was 2-7 times higher than actual doses used.

Conclusions: For many opioids, there are key differences between the actual doses used in clinical practice and the WHO's DDDs. The interpretation of opioid utilization studies using population-level DDDs may be limited, and a recalibration of the DDD for many opioids, or the reporting of opioid utilisation in Oral Morphine Equivalent doses is recommended.

This article is protected by copyright. All rights reserved. 


\section{Introduction}

Substantial increases in opioid prescribing are reported in many high income countries ${ }^{1}$, with increases in related harms. A key step in studying population-level opioid use is to present data using a common metric. The Defined Daily Dose (DDD, defined as "the assumed average maintenance dose per day for a drug used for its main indication in adults" ${ }^{\text {) }}$ ) was established for this purpose, and has been used in pharmacoepidemiology studies, by the International Narcotics Control Board, and by the World Health Organization in reporting on opioid utilisation ${ }^{1-3}$. The DDD allows the utilisation of different drugs with different doses and potencies to be quantified at the population level for national and international comparisons. For example, an estimate of 10 DDDs/1000 inhabitants per day indicates that $1 \%$ of the population (on average) receives what is defined as one dose of that drug daily.

There are challenges in using DDDs. They may be less useful in studies evaluating drug utilisation by older adults (in whom lower doses may be used); in studies that do not focus on a drug's main indication; or when there is a large discrepancy between the DDD and the prescribed or actual daily dose. This is a particular issue when examining opioid utilization because opioid doses are commonly titrated to response (i.e. adequate pain relief) and may not lie within "standard" therapeutic dose ranges. Finally, the DDD metric may not accuracy reflect the varying clinical potency of commonly used opioids, with some DDDs representing larger (morphine) equivalent doses than others ${ }^{3}$. 
As recent increases in opioid use have been largely for chronic non-cancer pain $(\mathrm{CNCP})^{4}$, it is timely to understand the potential applicability of the DDD metric for this indication. This study used data from a nationally representative cohort study of chronic pain patients prescribed opioids in order to assess to what extent the DDD metric reflects actual doses used in chronic pain treatment.

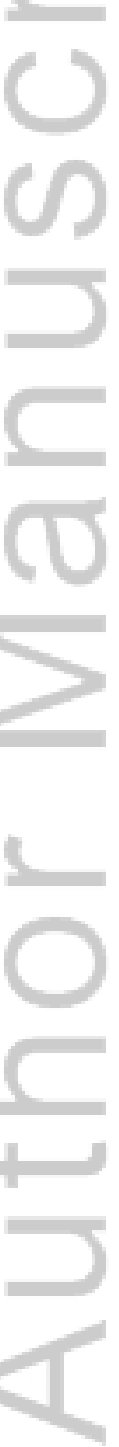

This article is protected by copyright. All rights reserved. 


\section{Methods}

\section{Participants and Procedure}

The Pain and Opioid IN Treatment (POINT) study examines patterns of pharmaceutical opioid use, adverse events and outcomes, in a prospective cohort of people prescribed opioids for chronic non-cancer pain $(\mathrm{CNCP})^{5}$. Study participants were recruited via Australian community pharmacies. Pharmacists were asked to approach customers that were prescribed strong opioids for CNCP for a period of greater than 6 weeks. This current study is based on a subset of 1101 POINT study participants (total $\mathrm{N}=1514$ ) who were interviewed by telephone at baseline between August 2012 and April 2013 and who provided a self-completed one-week medication diary to capture the names, strengths and doses of all medications taken in the previous week. The methodology of the larger cohort study has been described in detail elsewhere ${ }^{5}$

At study enrolment, POINT participants were: 18 years or older; living with CNCP; and had been taking a prescribed controlled opioid such as morphine, oxycodone or fentanyl for at least 6 weeks. A history of injecting drug use was not an exclusion criterion, but people who were currently prescribed methadone or buprenorphine for heroin dependence, or taking opioids for cancer pain, were not eligible for the POINT cohort study.

\section{Key measures}

This article is protected by copyright. All rights reserved. 
Full details of The POINT study measures are reported elsewhere ${ }^{5}$. Measures used in this study are:

Demographics: age, gender, marital status and current employment.

Pain history: the duration of pain, main types of pain and past and current analgesic use.

Opioid dose: the dose of each opioid was calculated using each participant's 7-day self-complete medication diary, which captured all medications taken in the past week. The opioid dose was calculated by dividing the total weekly dose by seven. Doses were calculated only for people who reported taking a specific opioid at least once in that week. All forms of each opioid (e.g. total dose of extended release and immediate release preparations of the same opioid) were included. We reported the median dose of each opioid, for those who used only that opioid, and for those who reported multiple opioids, expressed in oral morphine equivalents (OME) for the sample $^{6}$ (See Appendix 1 for the conversion factors used). Sensitivity analyses were conducted to determine the effect of concomitant acetaminophen use on opioid dose.

\section{Analyses}

Stata version 14.0SE (StataCorp, Texas, USA) was used to calculate descriptive statistics for the sample. We then compared median opioid dose with the WHO DDDs ${ }^{7}$. 


\section{Results}

\section{Sample characteristics}

The sample had a mean age of 58.5 years $(\mathrm{SD}=13.4)$. Just under half were male $(43 \%, \mathrm{n}=472)$ and just over half $(55 \%, \mathrm{n}=606)$ were married or living in a de facto relationship. Eighteen percent $(n=199)$ were currently employed or studying, and one third $(34 \%, n=375)$ were retired. Participants reported CNCP for a median of 11 years (IQR 5-22) and had been prescribed opioids continuously for a median of 4.0 years (IQR $1.5-10)$. The most common pain condition reported was back/neck pain. Other medications that participants reported using in the past month in the baseline survey included antidepressants $(53 \%, \mathrm{n}=583)$, regular paracetamol (acetaminophen) $(45 \%, \mathrm{n}=499)$, anti-inflammatories $(29 \%, \mathrm{n}=322)$ and anticonvulsants $(19 \%$, $\mathrm{n}=211)$

**Table 1 approximately here**

\section{Median opioid doses}

The DDD ranged from 0.6 to 7.1 times the actual daily dose taken (see Table 1). This range was comparable for those using single and multiple opioids.

For transdermal fentanyl and oral hydromorphone, the median dose was comparable with the DDD. For other opioids, the DDD was greater than usual doses taken: by a factor of 1.3-1.7 for 
morphine, 1.9-3.0 for oxycodone, and 6.0-7.1 for transdermal buprenorphine. Methadone was the exception, with the DDD representing 0.6 of the usual doses taken by participants. Sensitivity to determine the effect of concomitant acetaminophen use did not change these results.

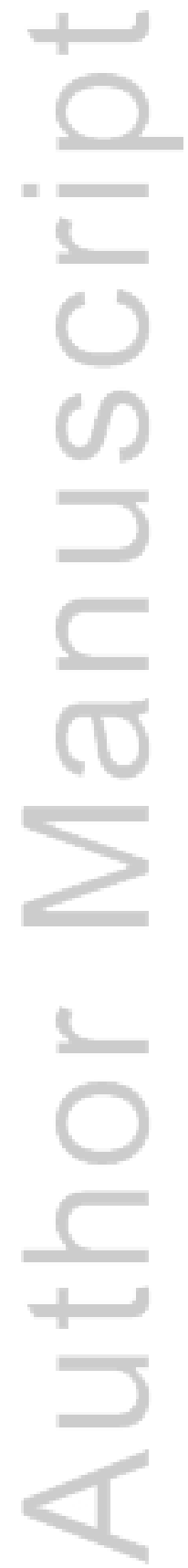

This article is protected by copyright. All rights reserved. 


\section{Discussion}

We examined the extent to which DDDs for opioids reflect contemporary chronic pain management. For some opioids (e.g. codeine and fentanyl), the average doses taken in current clinical practice were similar to the DDD. However, the DDD for the most commonly used strong opioids - oxycodone and buprenorphine - was 2-7 times greater than the actual doses taken. By contrast, the DDD for methadone was only 0.6 (or $40 \%$ lesser than) the actual dose. This suggests that the DDD metrics for opioids need validation.

These findings have important implications for studies that apply the DDD metric to examine population level opioid use. Where the DDD is greater than the doses taken, DDDs will underrepresent opioid use. Secondly, the variability in accuracy for different opioids complicates comparisons when the main opioid used changes. For example, in Australia, the observed large shifts from morphine to oxycodone and buprenorphine ${ }^{8}$ would be obscured at the population level because the DDDs of the latter opioids are much greater than doses used in practice.

Future opioid prescribing in chronic pain may become even less related to current DDDs if the guidelines from the US Centre for Disease Control (CDC) are followed ${ }^{9}$. These guidelines recommend caution using doses greater than 50mg OME (half the current DDD) and recommends not using doses above 90mg OME. This means that current DDDs may not reflect contemporary opioid prescribing practices but rather what are considered to be 'high-risk' doses 
in chronic pain treatment ${ }^{10,11}$. Given concerns with the relative accuracy of current DDDs and the further potential for changes in opioid dose recommendations, one possible solution may be to express opioid use at a population level using the OME metric. While there are known caveats in converting opioids to morphine equivalents due to estimates around relative potency, these same caveats apply to DDD. The difference is that the OME metric removes the additional assumptions that occur when dividing the quantity of drug used by a defined dose.

A strength of this study was that it recruited a national sample representative of chronic pain patients prescribed opioids ${ }^{11}$. Participants were recruited from community pharmacies rather than specialist pain clinics, potentially increasing the generalizability of the findings. In addition, the opioid doses used in this study represented self-reported (diary-based) doses taken over the week, rather than doses estimated from prescribing data, for which numerous caveats exist. The sample had been prescribed opioids for a median of 4 years, indicating that most were using stable doses of long-term opioids. The DDD metric may be less representative where opioids are used for shorter periods of time, and where opioid tolerance is not established (such as acute dosing). Future studies could examine how opioid doses in acute pain management relate to published DDDs.

The study faces the usual limitations of self-report data, although the study design used procedures to maximise the reliability of self-report ${ }^{12}$. Sample sizes for less frequently used 
opioids were also smaller. Our comparisons are based specifically on chronic pain treatment in Australia although the WHO DDDs reflect 'treatment of pain' and not specifically CNCP. Our findings may not be generalizable to treatment of other pain types, or CNCP treatment in other geographic regions. This concern is mitigated to some degree by similar findings in a study of prescribed opioid use in cancer patients in Italy, in which doses used were also often lower than the WHO DDDs, with the exception of fentanyl ${ }^{13}$. In countries where opioids are less available, lower doses of opioids may be used, so the DDD may be even less representative of use in those regions. Finally, as a DDD for methadone in pain treatment is not reported, we used the DDD for its use in opioid dependence. As methadone doses in opioid dependence are typically much greater (around $80 \mathrm{mg}$ per day ${ }^{14}$, with a trend towards increasing doses ${ }^{15}$ ), this suggests that the DDD for methadone also warrants review.

\section{Conclusions}

In summary, in a community sample of Australian CNCP patients, the DDD for many opioids did not reflect actual doses used in contemporary CNCP treatment. This may limit the application of DDD in pharmacoepidemiological studies of opioids. 


\section{Acknowledgments}

Thanks to Jessica Belcher, Sarah Freckleton, Bianca Hoban, Anika Martin, Ranira Moodley and Kimberly Smith NDARC, for their contribution to data collection, project investigators Michael Farrell, Tim Dobbins and the POINT advisory committee for their advice on the design and conduct of the larger study.

\section{Contribution of authors}

All authors had input into larger study design, SN conceptualized and conducted the analyses and drafted the first version of manuscript. All authors provided input on interpretation of analyses and reviewed subsequent drafts and a final version of this manuscript.

This article is protected by copyright. All rights reserved. 


\section{References}

1. Berterame S, Erthal J, Thomas J, et al. Use of and barriers to access to opioid analgesics: a worldwide, regional, and national study. Lancet 2016; 387(10028): 1644-56.

2. World Health Organisation. Defined Daily Dose: Definition and general considerations. 17/12/2009 2009. http://www.whocc.no/ddd/definition_and_general_considera/ (accessed $11 / 8 / 2015$.

3. Svendsen K, Borchgrevink P, Fredheim O, Hamunen K, Mellbye A, Dale O. Choosing the unit of measurement counts: the use of oral morphine equivalents in studies of opioid consumption is a useful addition to defined daily doses. Palliat Med 2011; 25(7): 725-32. 4. Sullivan MD, Howe CQ. Opioid Therapy for Chronic Pain in the US: promises and perils. Pain 2013; 154(0 1): S94-100.

5. Campbell G, Mattick R, Bruno R, et al. Cohort protocol paper: the Pain and Opioids In Treatment (POINT) study. BMC pharmacology \& toxicology 2014; 15(1): 17.

6. Nielsen S, Degenhardt L, Hoban B, Gisev N. A synthesis of oral morphine equivalents (OME) for opioid utilisation studies. . Pharmacoepidemiology and Drug Safety 2016; 25(6): 733-7.

7. World Health Organization Collaborating Center for Drug Statistics Methodology. ATC Index with DDDs. Olso: WHO; 2016.

8. Leong M, Murnion B, Haber PS. Examination of opioid prescribing in Australia from 1992 to 2007. Internal Medicine Journal 2009; 39(10): 676-81.

9. Dowell D, Haegerich TM, Chou R. CDC Guideline for Prescribing Opioids for Chronic Pain - United States, 2016. MMWR Recommendations and reports : Morbidity and mortality weekly report Recommendations and reports / Centers for Disease Control 2016; 65(1): 1-49. 10. Zedler B, Xie L, Wang L, et al. Risk Factors for Serious Prescription Opioid-Related Toxicity or Overdose among Veterans Health Administration Patients. Pain Med 2014; 15(11): 1911-29.

11. Campbell G, Nielsen S, Larance B, et al. Pharmaceutical opioid use and dependence among people living with chronic pain: Associations observed within the Pain and Opioids IN Treatment (POINT) cohort. Pain Med 2015; 16(9): 1745-58.

12. Chan DS. So why ask me? Are self report data really that bad? . In: Vandenberg CELaRJ, ed. Statistical and methodological myths and urban legends: Doctrine, verity and fable in the organizational and social sciences New York, NY: Routledge.; 2009: 309-35.

13. Chinellato A, Terrazzani G, Debetto P, et al. Retrospective analysis of opioid prescriptions in cancer patients in a northern Italian Region. British Journal of Clinical Pharmacology 2006; 62(1): 130-3.

14. Walley AY, Cheng DM, Pierce CE, et al. Methadone dose, take home status, and hospital admission among methadone maintenance patients. $J$ Addict Med 2012; 6(3): 186-90.

15. Pollack HA, D'Aunno T. Dosage Patterns in Methadone Treatment: Results from a National Survey, 1988-2005. Health Serv Res 2008; 43(6): 2143-63. 
Table 1: Characteristics of POINT participants according to type of opioid currently taken

\begin{tabular}{|c|c|c|c|c|c|c|c|c|c|c|}
\hline & $\begin{array}{l}\text { Total OME } \\
\text { (i.e. all } \\
\text { opioids) } \\
\text { N=1101 }\end{array}$ & $\begin{array}{c}\text { Morphine } \\
(\mathbf{n}=151)\end{array}$ & $\begin{array}{l}\text { Oxycodone } \\
(\mathbf{n}=557)\end{array}$ & $\begin{array}{l}\text { Oxycodone- } \\
\text { naloxone } \\
(\mathbf{n}=\mathbf{1 2 8})\end{array}$ & $\begin{array}{c}\text { Hydro- } \\
\text { morphone } \\
(\mathbf{n}=37)\end{array}$ & $\begin{array}{c}\text { Fentanyl } \\
\text { (Transdermal) } \\
(\mathbf{n}=\mathbf{1 5 6})\end{array}$ & $\begin{array}{c}\text { Buprenorphine } \\
\text { (Transdermal) } \\
(\mathbf{n}=\mathbf{2 3 3})\end{array}$ & $\begin{array}{l}\text { Methadone } \\
\quad(\mathrm{n}=\mathbf{4 2})\end{array}$ & $\begin{array}{l}\text { Codeine* } \\
(n=172)\end{array}$ & $\begin{array}{c}\text { Tramadol* } \\
(\mathbf{n}=\mathbf{6 0})\end{array}$ \\
\hline $\begin{array}{l}\text { WHO DDD } \\
\text { (in mg of each } \\
\text { opioid) }\end{array}$ & $\begin{array}{c}100 \\
\text { (morphine } \\
\text { mg) }\end{array}$ & 100 & 75 & 75 & 20 & 1.2 & 1.2 & $25^{\wedge}$ & 100 & 300 \\
\hline WHO DDD in OME & 100 & 100 & 112.5 & 112.5 & 100 & 112.5 & 91.6 & 117.5 & 10 & 60 \\
\hline & \multicolumn{10}{|c|}{ Opioid dose for specific opioids for full sample (includes participants using single and multiple opioids in the previous week) } \\
\hline $\begin{array}{l}\text { Median dose (IQR) } \\
\text { (in mg of each } \\
\text { opioid) }\end{array}$ & $\begin{array}{c}73 \text { (36- } \\
145)\end{array}$ & $\begin{array}{c}60.0 \\
(37.9-120)\end{array}$ & $\begin{array}{c}30(10- \\
60)\end{array}$ & $\begin{array}{c}30(18.6- \\
40)\end{array}$ & $\begin{array}{c}18.0(8- \\
32)\end{array}$ & $\begin{array}{c}1.2(0.6- \\
1.6)\end{array}$ & $0.2(0.2-0.5)$ & $\begin{array}{c}40(29- \\
60)\end{array}$ & $\begin{array}{c}102.9(60- \\
180)\end{array}$ & $\begin{array}{c}200(50- \\
400)\end{array}$ \\
\hline DDD/Median dose & 1.4 & 1.7 & 2.5 & 2.5 & 1.1 & 1.0 & 7.1 & 0.6 & 1.0 & 1.5 \\
\hline & \multicolumn{10}{|c|}{ Opioid dose limited to those that reported use of a single opioid in the previous week (i.e. excludes those using multiple opioids) } \\
\hline 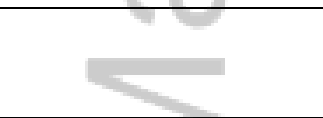 & - & $\begin{array}{c}\text { Morphine } \\
(\mathbf{n}=58)\end{array}$ & $\begin{array}{l}\text { Oxycodone } \\
(\mathrm{n}=\mathbf{2 1 0})\end{array}$ & $\begin{array}{l}\text { Oxycodone } \\
\text {-naloxone } \\
(n=56)\end{array}$ & $\begin{array}{c}\text { Hydro- } \\
\text { morphone } \\
(\mathbf{n}=13)\end{array}$ & $\begin{array}{c}\text { Fentanyl } \\
(\mathbf{n}=73)\end{array}$ & $\begin{array}{c}\text { Buprenorphin } \\
\text { e } \\
(\mathbf{n}=\mathbf{1 2 1})\end{array}$ & $\begin{array}{c}\text { Methado } \\
\text { ne } \\
(\mathbf{n}=\mathbf{2 0})\end{array}$ & $\begin{array}{l}\text { Codeine } \\
(\mathbf{n}=9) *\end{array}$ & $\begin{array}{l}\text { Tramadol } \\
(\mathrm{n}=3)^{*}\end{array}$ \\
\hline $\begin{array}{l}\text { Median daily mg } \\
\text { for those using only } \\
\text { that opioid }\end{array}$ & - & $\begin{array}{c}75.0(40.0 \\
-120.0)\end{array}$ & $\begin{array}{c}40.0(20.0- \\
90.0)\end{array}$ & $\begin{array}{c}25(17.5- \\
40.0)\end{array}$ & $\begin{array}{c}16.0(8.0 \\
-32.0)\end{array}$ & $\begin{array}{c}1.2(0.6- \\
1.2)\end{array}$ & $\begin{array}{c}0.24(0.24- \\
0.48)\end{array}$ & $\begin{array}{c}40.0(20 \\
-55.0)\end{array}$ & $\begin{array}{c}60.0(60.0 \\
-180.0)\end{array}$ & $\begin{array}{c}314.3 \\
(200.0- \\
857.1)\end{array}$ \\
\hline DDD/Median dose & & 1.3 & 1.9 & 3.0 & 1.3 & 1.0 & 6.0 & 0.6 & 1.7 & 1.0 \\
\hline
\end{tabular}

$\wedge$ DDD reflects use for opioid dependence as DDD not listed for pain, all other DDDs are 'based on the treatment of pain' under the Anatomical Therapeutic Chemical (ATC) classification system code N02A 'analgesics'. DDDs reflect oral use except for fentanyl and buprenorphine.

*Weak opioid, low n as most participants are concurrently taking a strong opioid, giving lower confidence in estimates

This article is protected by copyright. All rights reserved. 
Sensitivity analyses were conducted to determine if the DDD was lower in those also taking acetaminophen and these found that for all opioids other than oxycodone, no change in daily OME dose was detected. For oxycodone, a lower median dose was found for those taking acetaminophen ( $21 \mathrm{mg}$ ) compared to those that were not taking acetaminophen (40mg). The median DDD for both groups was below the published WHO DDD for oxycodone.

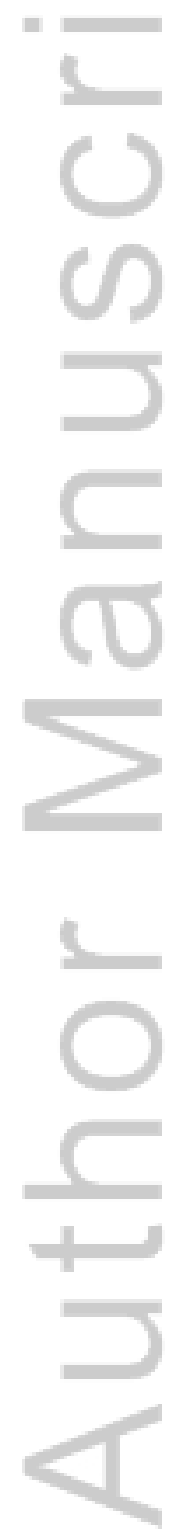

This article is protected by copyright. All rights reserved. 


\begin{tabular}{|l|l|}
\hline Product & $\begin{array}{l}\text { Oral Morphine Equivalent } \\
\text { conversion factor (to convert to } \\
\text { mg/day) }\end{array}$ \\
\hline ORAL PREPARATIONS & $\mathbf{0 . 1}$ \\
\hline codeine & $\mathbf{5}$ \\
\hline hydromorphone & $\mathbf{4 . 7}$ \\
\hline methadone & $\mathbf{1}$ \\
\hline morphine & $\mathbf{1 . 5}$ \\
\hline oxycodone & $\mathbf{3}$ \\
\hline oxymorphone & $\mathbf{0 . 2}$ \\
\hline tramadol & $\begin{array}{l}\text { TRANSDERMAL PREPARATIONS (multiple patch } \\
\text { strength in hourly rate by conversion factor) }\end{array}$ \\
\hline buprenorphine & $\mathbf{2 . 2}$ \\
\hline fentanyl & $\mathbf{2 . 7}$ \\
\hline
\end{tabular}

Appendix 1. Conversion factors used to calculate Oral Morphine Equivalents doses ${ }^{6}$

This article is protected by copyright. All rights reserved. 


\section{University Library}

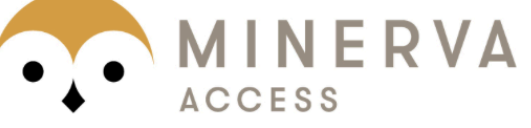

A gateway to Melbourne's research publications

Minerva Access is the Institutional Repository of The University of Melbourne

\section{Author/s:}

Nielsen, S;Gisev, N;Bruno, R;Hall, W;Cohen, M;Larance, B;Campbell, G;Shanahan, M;Blyth, F;Lintzeris, N;Pearson, S;Mattick, R;Degenhardt, L

Title:

Defined daily doses (DDD) do not accurately reflect opioid doses used in contemporary chronic pain treatment

Date:

2017-05-01

Citation:

Nielsen, S., Gisev, N., Bruno, R., Hall, W., Cohen, M., Larance, B., Campbell, G., Shanahan, M., Blyth, F., Lintzeris, N., Pearson, S., Mattick, R. \& Degenhardt, L. (2017). Defined daily doses (DDD) do not accurately reflect opioid doses used in contemporary chronic pain treatment. PHARMACOEPIDEMIOLOGY AND DRUG SAFETY, 26 (5), pp.587-591. https:// doi.org/10.1002/pds.4168.

Persistent Link:

http://hdl.handle.net/11343/292336 